Integrated Circuit Design 


\section{Macmillan New Electronics Series}

Series Editor: Paul A. Lynn

Paul A. Lynn, Radar Systems

A. F. Murray and H. M. Reekie, Integrated Circuit Design 


\title{
Integrated Circuit Design
}

\author{
Alan F. Murray
}

and

\section{H. Martin Reekie}

Department of Electrical Engineering Edinburgh University

Macmillan New Electronics

Introductions to Advanced Topics

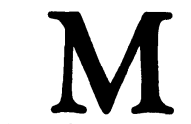

MACMILLAN

EDUCATION 
All rights reserved. No reproduction, copy or transmission of this publication may be made without written permission.

No paragraph of this publication may be reproduced, copied or transmitted save with written permission or in accordance with the provisions of the Copyright Act 1956 (as amended), or under the terms of any licence permitting limited copying issued by the Copyright Licensing Agency, 7 Ridgmount Street, London WC1E 7AE.

Any person who does any unauthorised act in relation to this publication may be liable to criminal prosecution and civil claims for damages.

First published 1987

Published by

MACMILLAN EDUCATION LTD

Houndmills, Basingstoke, Hampshire RG21 2XS

and London

Companies and representatives

throughout the world

British Library Cataloguing in Publication Data

Murray, A. F.

Integrated circuit design.-(Macmillan

new electronics series).

1. Integrated circuits-Design and construction

I. Title II. Reekie, H. M. 621.381'73 TK7874

ISBN 978-0-333-43799-5 
To Glynis and Christa 


\section{Contents}

Series Editor's Foreword $x i$

Preface xii

Section I 1

1 General Introduction to Microelectronics $\quad 3$

1.1 History of Microelectronics 3

1.2 The Current and Future State of Microelectronics 9

$\begin{array}{lr}1.3 \text { Production of an Electronic System } & 10\end{array}$

$\begin{array}{ll}1.4 \text { Systems-on-a-chip } & 11\end{array}$

$\begin{array}{ll}1.5 \text { Layout of Book } & 13\end{array}$

2 Introduction to MOS (Metal-Oxide-Semiconductor) Devices and Logic 14

$\begin{array}{ll}2.1 \text { The MOS Transistor: Physical Behaviour } & 14\end{array}$

2.1.1 The MOS Transistor Switch: Descriptive 16

2.1.2 The MOS Transistor Switch: Device Equations 19

$\begin{array}{lll}2.1 .3 & \text { MOS Transistor Types } & 22\end{array}$

2.2 The Complementary MOS (CMOS) Inverter 24

2.2.1 The CMOS Inverter: Logical Performance 24

2.2.2 The CMOS Inverter: Speed Performance 26

2.3 CMOS Logic $\quad 32$

2.3.1 CMOS Logic Gates: Logical Performance 32

2.3.2 CMOS Logic Gates: Speed Performance 35

$\begin{array}{ll}2.4 \text { nMOS Logic } & 35\end{array}$

2.4.1 nMOS Inverter: Simple Analysis 36

2.4.2 nMOS Logical Performance 39

2.5 Synchronous Logic: An Introduction 41

2.6 Summary $\quad 42$ 
3 Fabrication of Silicon Integrated Circuits 43

3.1 Wafer Production $\quad 44$

3.2 Production of Integrated Circuit Masks 44

3.3 Photolithography $\quad 46$

$\begin{array}{ll}3.4 \text { Oxidation } & 48\end{array}$

$\begin{array}{ll}3.5 \text { Diffusion } & 48\end{array}$

3.5.1 Constant Source Diffusion $\quad 50$

3.5.2 Limited Source Diffusion $\quad 50$

3.5.3 Practical Diffusion Techniques $\quad 52$

$\begin{array}{lll}3.5 .4 & \text { Typical Diffusion Apparatus } & 52\end{array}$

3.5.5 Lateral Under-Diffusion $\quad 53$

3.6 Ion Implantation $\quad 54$

3.7 Low Pressure Chemical Vapour Deposition (LPCVD) 57

$\begin{array}{ll}3.8 \text { Metallisation } & 59\end{array}$

$\begin{array}{ll}3.9 \text { Example of nMOS Process } & 60\end{array}$

4 Design Rules $\quad 63$

4.1 Contents of Design Rules $\quad 63$

4.1.1 Geometric Design Rules $\quad 63$

4.1.2 Electrical Design Rules $\quad 66$

4.1.3 Mandatory Features $\quad 66$

4.2 Process-Independent Geometric Design Rules 66

4.2.1 Use of Buried Contacts to Define Transistor Gate Lengths 72

4.3 Process-Independent Electrical Design Rules and Mandatory

$\begin{array}{ll}\text { Features } & 72\end{array}$

4.4 Advantages and Disadvantages of Process-Independent Design
Rules

$\begin{array}{ll}\text { 4.5 Consequences of Breaking Design Rules } & 74\end{array}$

5 Other Integrated Circuit Technologies $\quad \mathbf{7 5}$

$\begin{array}{ll}5.1 \text { Silicon Bipolar Technologies } & 75\end{array}$

5.1.1 Resistor Transistor Logic (RTL) 76

$\begin{array}{lll}\text { 5.1.2 Diode Transistor Logic (DTL) } & 77\end{array}$

5.1.3 Transistor Transistor Logic (TTL) 78

$\begin{array}{lll}\text { 5.1.4 Emitter Coupled Logic (ECL) } & 79\end{array}$

5.1.5 Integrated Injection Logic $\left(\mathrm{I}^{2} \mathrm{~L}\right) \quad 82$

$\begin{array}{ll}5.2 \text { Silicon-on-Sapphire (SOS) } & 82\end{array}$

5.3 Gallium Arsenide (GaAs) $\quad 83$

5.4 Comparison between Logic Families $\quad 84$

6 Integrated Circuits: from Concept to Silicon $\quad 86$

6.1 Gate Array/Masterslice Design 86

6.1.1 Gate Arrays with Wiring Channels ('Streets and Houses') 87

6.1.2 Sea-of-Gates Array $\quad 88$ 
6.1.3 Gate Arrays: Advantages and Disadvantages $\quad 89$

6.2 Standard Cell Design 90

6.2.1 Standard Cell Design: Advantages and Disadvantages 92

6.3 Full Custom (Handcrafted) ASIC Design 93

6.4 Programmable Logic Array (PLA) Design 95

6.5 Summary and Conclusions 98

7 Design Discipline and Computer Aided Design (CAD) and Test 100

$\begin{array}{ll}7.1 \text { Hierarchical Design and Macros } & 102\end{array}$

7.1.1 Top-down Design and Partitioning 103

$\begin{array}{ll}7.2 \text { Design Verification by Simulation } & 104\end{array}$

$\begin{array}{ll}\text { 7.2.1 High Level Simulation } & 105\end{array}$

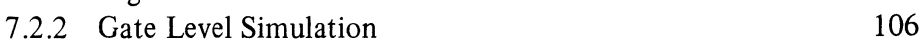

$\begin{array}{lll}7.2 .3 & \text { Switch Level Simulation } & 108\end{array}$

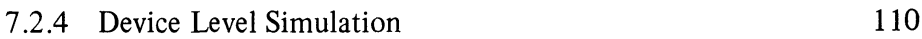

$\begin{array}{ll}7.3 \text { Physical Design and Chip Layout } & 110\end{array}$

7.3.1 Traditional Graphic Editors $\quad 111$

$\begin{array}{lll}\text { 7.3.2 Symbolic Editors } & 111\end{array}$

7.3.3 Automatic Routing and Placement 111

$\begin{array}{lll}\text { 7.3.4 Silicon Compilers } & 112\end{array}$

7.3.5 Circuit Extraction and Re-Simulation 113

$\begin{array}{ll}\text { 7.3.6 Generation of Fabrication Data } & 113\end{array}$

$\begin{array}{ll}7.4 \text { Integrated Circuit Testing } & 113\end{array}$

7.4.1 Test Pattern Generation $\quad 113$

$\begin{array}{lll}7.4 .2 & \text { Test Pattern Validation } & 115\end{array}$

$\begin{array}{ll}\text { 7.4.3 Design for Testability } & 116\end{array}$

$\begin{array}{ll}\text { 7.4.4 Application of Test Patterns } & 116\end{array}$

$\begin{array}{lr}\text { Section II } & 117\end{array}$

8 The GATEWAY Gate Array Design Exercise 119

$\begin{array}{ll}8.1 \text { Introduction } & 119\end{array}$

8.2 The GATEWAY Philosophy 119

8.3 The ED500 Gate Array 120

8.3.1 The 'Hardwired' Inverter M3/M4 124

8.3.2 Use of Transistors M1 and M2 125

8.3.3 ED500 Gate Array Performance 129

8.4 The ED500C Gate Array 130

8.4.1 The 'Hardwired' Inverter M3/M4 132

8.4.2 Use of Transistors M1 and M2 133

8.4.3 ED500C Gate Array Performance 135

8.5 ED500/ED500C Speed Performance Calculations 139

8.6 Design Methods, Discipline and the GATEWAY CAD 140 
8.7 GATEWAY Project Assignment 141

8.7.1 Circuit Description and Details 141

8.7.2 Project Management 143

$\begin{array}{ll}\text { 8.7.3 Costing of Project } & 145\end{array}$

Appendix: Inverter Output Rise Time 146

$\begin{array}{ll}\text { Bibliography } & 148\end{array}$

$\begin{array}{ll}\text { Index } & 149\end{array}$ 


\section{Series Editor's Foreword}

The rapid development of electronics and its engineering applications ensures that new topics are always competing for a place in university and polytechnic courses. But it is often difficult for lecturers to find suitable books for recommendation to students, particularly when a topic is covered by a short lecture module, or as an 'option'.

Macmillan New Electronics offers introductions to advanced topics. The level is generally that of second and subsequent years of undergraduate courses in electronic and electrical engineering, computer science and physics. Some of the authors will paint with a broad brush; others will concentrate on a narrower topic, and cover it in greater detail. But in all cases the titles in the Series will provide a sound basis for further reading of the specialist literature, and an up-to-date appreciation of practical applications and likely trends.

The level, scope and approach of the Series should also appeal to practising engineers and scientists encountering an area of electronics for the first time, or needing a rapid and authoritative update.

Paul A. Lynn 


\section{Preface}

There are several excellent textbooks available that treat Integrated Circuit (IC) Design at a level appropriate to final year students, to practising designers or to postgraduates. Some of these advanced texts have an 'engineering' bias, and give a detailed treatment of the technology underlying integrated circuits. Others have a 'computer' science systems' leaning, concentrate on methods of IC design, and do not discuss the underlying technology beyond the barest fundamentals. These textbooks are all expensive, and their use is only justified in an advanced course, where they form one of the major (or even the major) text for the course.

Integrated circuit technology has now reached a stage of maturity where it forms an integral part of most undergraduate courses in Electrical Engineering, and indeed many Computer Science and Physics courses. It is therefore no longer appropriate to leave IC design as merely a 'final year option'. It is necessary to introduce the subject at a much earlier stage via a 'primer' course, leaving advanced material to a later course, which only enthusiasts need attend. There is at present no inexpensive text suitable for introducing pre-final year (or younger) undergraduates to IC Design, and it is irresponsible to recommend an advanced text for an introductory course. This book is intended to be a 'first' book of IC design that can stand alone as a text for non-specialists, or can lead to a more advanced course in a subsequent year of study.

The first chapter of the book puts the development of microelectronics in historical perspective, so that its meteoric pace may be appreciated. The focus of the book is on design, and the technological details are restricted to those essential to performing and understanding a simple IC design. However, the book is intended to be a true introduction, which would be incomplete without some underlying details. We have assumed only a knowledge of elementary Boolean algebra, of the barest details of electron/hole physics, and of simple linear circuit analysis (Ohm's Law!). The book is therefore self-contained for the reader who understands these fundamentals. From this basis, the physics of MOS transistor 
devices is discussed in chapter 2 , in a simplified form appropriate to what we need to get out of it at this stage.

Chapters 3 and 4 take the same attitude to IC technology as chapter 2 took to device physics. Chapter 3 describes the processes by which MOS devices are fabricated. This treatment allows us, in chapter 4 , to extract from the apparent alchemy of the fabrication process a set of specifications that allow a designer remote from the manufacturing site to prepare correct IC designs for fabrication. These are the 'design rules' for the process. Although this book deals in detail with only Metal-Oxide-Silicon (MOS) technology, other IC technologies have application areas which, although smaller than MOS, should not be disregarded. Chapter 5 catalogues the more important 'alternative' IC technologies, and highlights their strengths and weaknesses.

There are many ways of taking an IC specification or concept through the IC design process to produce a working chip. Each method has its advantages and shortcomings, and although section II of this book concentrates on only one of these methods, it is essential that the others be understood. Chapter 6 discusses the three main classes of IC design approach, and indicates the considerations of performance, cost and expediency that lead to a choice.

The design of a complex integrated circuit containing millions of transistors is a difficult task, which would be impossible without the correct use of Computer Aided Design (CAD) tools. The importance of these tools in the IC design process has become such that they have partially dictated the speed and direction of further development. Even an introductory text such as this must impart a feel for the range and scope of the CAD techniques for IC design. While chapter 7 makes no attempt to deal with the inner workings of CAD software, it does describe the major areas of IC design where CAD is necessary. In addition, discussion of IC testing is included in this chapter, as the field of test is so heavily reliant upon good supporting CAD. The need for discipline and care in IC design is acknowledged universally, and the fundamental techniques of hierarchical design and extensive simulation are ubiquitous. Chapter 7 explains how CAD tools encourage, aid, and occasionally enforce good design practice.

In learning any new skill, there is no substitute for practice. Integrated circuit design is no exception to this rule, and it is the aim of this book to equip its reader to perform a simple IC design. The first section of the book (chapters 1-7) constitute the background and technological detail essential to such an exercise. The second section comprises, in one chapter, a design 'manual' for a Gate Array design exercise ('GATEWAY') that has been used at the University of Edinburgh since 1982. The exercise is set in industrial terms, and includes timescales, costing details and other constraints such as would be encountered in an industrial setting. The project is designed to fit the academic year, and is used as part of the laboratory/course work at Edinburgh, in parallel with other activities. The assignment itself is deliberately straightforward and the circuit small, as we have found no benefit in the use of a large design. Indeed the effect of a large IC design is likely to be negative, as a clear view of the con- 
ceptual material is obscured by the sheer size of the task. It is our experience that the industrial setting, and the feeling of designing to a 'real' specification produces a positive reaction from students. Healthy competition grows to see who will do the 'best' design, and the learning potential is enormous. There is a set of software tools available to enhance the GATEWAY exercise, although it can be used without them. The software can be obtained from Unived Technologies Ltd, 16 Buccleuch Place, Edinburgh EH8 9LN.

In summary, this book should arm a pre-final year student with the knowledge to ease his passage into and through a more advanced IC Design course and textbook. In addition, it can stand alone to give a complete appreciation of the essentials of IC design to the non-specialist engineer or scientist.

The authors are grateful for the encouragement and advice of all their colleagues and of students who have performed the GATEWAY exercise. In particular, we wish to acknowledge a debt to Professor Mervyn Jack, the original architect of the GATEWAY exercise. The GATEWAY software was written with the help of Timothy Lees, and the microcomputer-based full custom graphic editor with the help of Frances Cranston. Tony Bramley drew the outline diagrams for the figures used throughout the book. We thank Professor John Mavor for his support as an advisor, and also in his capacity as Head of the Electrical Engineering Department at the University of Edinburgh. The collective expertise of the department, the friendship of the rest of its members and the overall environment have played no small part in the history of this book.

University of Edinburgh

Dept of Electrical Engineering

The King's Buildings

Edinburgh, EH9 3JL
Alan F. Murray

H. Martin Reekie 